\title{
DINÂMICA DE SISTEMAS INTEGRADOS DE MANEJO DE UM SOLO NO DESENVOLVIMENTO DA CULTURA DO MILHO
}

\author{
Arystides Resende Silva* \\ Agust Sales** \\ Eduardo Jorge Maklouf Carvalho*** \\ Carlos Alberto Costa Veloso ${ }^{* * * *}$
}

RESUMO: O presente estudo objetivou avaliar a dinâmica de sistemas integrados de manejo de um Latossolo Amarelo no desenvolvimento da cultura do milho. O delineamento experimental utilizado foi o de blocos casualizados, com quatro repetições. Os tratamentos foram compostos por três cultivos de milho, em sistema de integração Lavoura-Pecuária-Floresta (iLPF) (consorciado com Brachiaria ruziziensis e intercalado com eucalipto), sistema Santa Fé (cultivo integrado com Brachiaria ruziziensis) e em sistema Convencional. Foi realizada a determinação da altura (m) de planta e espiga do milho, teor de umidade dos grãos (\%), produtividade de grãos $\left(\mathrm{kg} \cdot \mathrm{ha}^{-1}\right.$, saca.ha ${ }^{-1} \mathrm{e} \mathrm{kg}$.planta $\left.{ }^{-1}\right)$ e número de plantas.ha ${ }^{-1}$. A altura de planta e a altura de espiga não apresentaram diferença em função dos sistemas utilizados. Os sistemas iLPF e Santa Fé obtiveram os maiores valores de produção (kg.ha-1; saca.ha ${ }^{1}$ ), não diferindo entre si. Proporcionaram também maior produção por indivíduo, sendo cerca de 36\% superior à obtida no sistema Convencional. A Brachiaria ruziziensis consorciada com milho favoreceu o aumento na produção de grãos por área e por indivíduo em comparação ao sistema Convencional.

PALAVRAS-CHAVE: Características agronômicas; Eucalipto; Produção de grãos.

\section{THE DYNAMICS OF INTEGRATED SYSTEMS IN SOIL MANAGEMENT IN CORN CROP}

ABSTRACT: The dynamics of integrated management systems in Yellow Latisol soil in the development of corn crop is assessed. Experiment consisted of randomized

\footnotetext{
* Doutor em Agronomia em Solos e Nutrição de Plantas pela Universidade Federal de Lavras (UFLA), Lavras (MG), Brasil; Pesquisador A Embrapa Amazônia Oriental, Belém (PA); E-mail: arystides.silva@embrapa.br

** Discente de graduação em Engenharia Florestal pela Universidade do Estado do Pará (UEPA), Paragominas (PA), Brasil.

*** Doutor em Solos e Nutrição de Plantas pela Escola Superior de Agricultura Luiz de Queiroz; Pesquisador-A da Embrapa Amazônia Oriental, Brasil.

${ }^{* * * *}$ Doutor em Agronomia pela Escola Superior de Agricultura Luiz de Queiroz; Pesquisador-A da Empresa Brasileira de Pesquisa Agropecuária, Brasil.
} 
blocks with four replications. Treatments comprised three corn cultures within the Agriculture-Livestock-Forest Integration (iLPF) system (combined with Brachiaria ruziziensis and intercalated with eucalyptus), Santa Fé system (integrated culture with Brachiaria ruziziensis) and conventional system. Height (m) of corn plant and cob, humidity rate of grains (\%), grain productivity (kg.ha ${ }^{-1}$, sack.ha ${ }^{-1}$ and kg.plant $\left.{ }^{-1}\right)$ and number of plants.ha ${ }^{-1}$ were analyzed. Plant and cob height did not reveal any difference within the analyzed systems. Further, iLPF and Santa Fé systems had the highest production rates $\left(\mathrm{kg} \cdot \mathrm{ha}^{-1}\right.$; sack.ha $\left.{ }^{-1}\right)$, with no difference between them. They also had the highest production per unit, approximately $30 \%$ higher than that obtained in the Conventional system. Brachiaria ruziziensis combined with corn enhanced increase in grain production per area and per unit when compared to results for the Conventional system.

KEY WORDS: Agronomic characteristics; Eucalyptus; Grain production.

\section{INTRODUÇÃO}

O milho é uma das culturas agrícolas mais produzidas no mundo, sendo o Brasil o terceiro maior produtor com 7,5\% de participação, ficando atrás da China e Estados Unidos (EMBRAPA, 2013). No Brasil, é a segunda cultura mais cultivada com cerca de 15,1 milhões de hectares plantados e 79 milhões de toneladas de produção (CONAB, 2015).

O milho possui grande importância na formação da renda agrícola, é matériaprima na indústria e devido sua composição nutricional contribui na alimentação humana e animal entrando como componente básico (SANTOS, 2010). Contudo, a utilização de sistemas e novas técnicas de manejo integrado do solo são de essencial importância para tornar o cultivo social e ambientalmente sustentável.

Os sistemas integrados de manejo do solo influenciam positivamente a reciclagem de nutrientes e os teores de matéria orgânica e nutrientes no solo, em razão da grande produção de matéria orgânica e elevado volume de raízes em profundidade (CALONEGO; BORGHI; CRUSCIOL, 2011a; CRUSCIOL; BORGHI, 2007), permitindo maior produção de grãos por hectare ao produtor do que o monocultivo (BRINTHA; SERAN, 2009; GUEDES et al., 2010; SOUZA et al., 2011).

Dentre os sistemas mais utilizados, o sistema de integração Lavoura- 
Pecuária-Floresta (iLPF) destaca-se por possibilitar, de modo sustentável, uma maior produção por área através do manejo de culturas consorciadas em sucessão de rotação potencializando os efeitos sinergéticos entre as espécies vegetais e a criação de animais (BALBINO et al., 2011). O sistema iLPF auxilia no aumento das interações biológicas entre os cultivos agrícolas, árvores e animais e reduz os riscos de erosão mantendo ou elevando os estoques de matéria orgânica quando comparado com outros modelos agrícolas (AGUIAR et al., 2010; MOLUA, 2005).

Outra importante opção é o sistema Santa Fé pelo cultivo de culturas anuais, especialmente o milho, consorciado com forrageiras, principalmente as do gênero Brachiaria. O sistema é realizado anualmente, o plantio da forragem pode ser realizado simultaneamente à cultura anual ou entre 10 a 20 dias após a emergência da mesma. O cronograma de atividades do produtor não precisa ser alterado e não são necessários maquinário e implementos especializados para a implantação (SOUZA et al., 2008).

Nestes sistemas, o grande desenvolvimento inicial das culturas anuais exerce alta competição sobre as forrageiras, evitando a redução da capacidade de produção dos grãos e favorecendo o aumento da produção de grãos, fibras, carne, leite, madeira e de agroenergia a baixos custos em função da energia sinergética criada entre pastagem, lavoura e árvores. O solo é manejado de forma sustentável e viável economicamente quando relacionado aos modelos mais especializados (NASCIMENTO; CARVALHO, 2011). Diante do exposto, o objetivo deste trabalho foi avaliar a dinâmica de sistemas integrados de manejo de um Latossolo Amarelo no desenvolvimento da cultura do milho BRS 1055.

\section{MATERIAL E MÉTODOS}

O estudo foi realizado na Fazenda Vitória, município de Paragominas, Estado do Pará (altitude de 89 metros a $02^{\circ} 57^{\prime} 29,47^{\prime}$ ' S de latitude e $47^{\circ} 23$ '10,37" W de longitude). O clima da região é do tipo Aw, pela classificação de Koppen. O solo foi classificado como Latossolo Amarelo textura argilosa (EMBRAPA, 2006), sendo as propriedades químicas e granulométricas analisadas antes da implantação 
do experimento nas profundidades 0-10 e 10-20 cm, utilizando a metodologia da EMBRAPA (1997), exceto a matéria orgânica (MO) que foi determinada pelo método de Walkley e Black, proposto em Black (1965) (Tabela 1).

Tabela 1. Propriedades ${ }^{1}$ químicas e granulométricas da área experimental nas profundidades 0-10 e 10-20 cm, Fazenda Vitória, Paragominas (PA), 2012

\begin{tabular}{|c|c|c|c|c|c|c|c|c|c|c|c|}
\hline $\begin{array}{l}\text { Prof. } \\
(\mathrm{cm})\end{array}$ & $\begin{array}{c}\mathrm{pH} \\
\left(\mathrm{H}_{2} \mathrm{O}\right)\end{array}$ & M.O. & $\mathrm{P}$ & $\mathrm{Ca}$ & $\mathrm{Mg}$ & K & $\mathrm{Al}$ & $\mathrm{H}+\mathrm{Al}$ & Areia & Silte & Argila \\
\hline & & $\begin{array}{l}(\mathrm{dag} . \\
\left.\mathrm{kg}^{-1}\right)\end{array}$ & $\begin{array}{l}(\mathrm{mg} . \\
\left.\mathrm{kg}^{-1}\right)\end{array}$ & \multicolumn{5}{|c|}{$\mathrm{cmolc} \mathrm{dm}^{-3}$} & \multicolumn{3}{|c|}{ g. $\mathrm{kg}^{-1}$} \\
\hline $0-10$ & 5,88 & 2,54 & 5,67 & 3,88 & 1,22 & 0,46 & 0,10 & 3,74 & 56 & 284 & 660 \\
\hline $10-20$ & 6,27 & 1,82 & 9,17 & 4,80 & 1,13 & 0,24 & 0,10 & 2,34 & 43 & 232 & 725 \\
\hline
\end{tabular}

${ }^{1}$ Análises realizadas no laboratório de Solos da Embrapa Amazônia Oriental. MO = Matéria Orgânica; $\mathrm{P}=$ Fósforo; $\mathrm{Ca}=$ Cálcio; $\mathrm{Mg}=$ Magnésio; $\mathrm{K}=$ Potássio; $\mathrm{Al}=$ Alumínio; $\mathrm{H}+\mathrm{Al}=$ Hidrogênio + Alumínio.

A precipitação anual apresenta média de $1743 \mathrm{~mm}$. A temperatura média anual varia entre $23,3^{\circ} \mathrm{C}$ a $27,3^{\circ} \mathrm{C}$ e a umidade relativa do ar média anual é de $81 \%$. Os dados meteorológicos referentes ao período de realização do experimento estão apresentados na Tabela 2 .

Tabela 2. Precipitação, umidade relativa (UR) e temperatura média durante a realização do experimento, Paragominas (PA), 2012

\begin{tabular}{ccccccc}
\hline Dados & $\mathrm{Fev} / 2012$ & $\mathrm{Mar} / 2012$ & $\mathrm{Abr} / 2012$ & $\mathrm{Mai} / 2012$ & $\mathrm{Jun} / 2012$ & $\mathrm{Jul} / 2012$ \\
\hline $\begin{array}{c}\text { Precipitação } \\
(\mathrm{mm})\end{array}$ & 433 & 313 & 278 & 153 & 67 & 55 \\
$\begin{array}{c}\text { Temperatura } \\
\left.\text { média ( }{ }^{\circ} \mathrm{C}\right)\end{array}$ & 25,3 & 25,6 & 25,5 & 25,4 & 25,8 & 25,9 \\
UR (\%) & 87,0 & 89,0 & 88,0 & 90,5 & 83,0 & 80,5 \\
\hline
\end{tabular}

Fonte: Inmet (2015)

O experimento foi composto por um sistema de integração LavouraPecuária-Floresta (iLPF) implantado em fevereiro de 2009, ocupando uma área de 4,05 ha com cultivo de milho (BRS 1030) em consórcio com Brachiaria ruziziensis 
e intercalado com renques de eucalipto (Eucalyptus urophylla). Para o arranjo espacial das árvores empregou-se o plantio em renques, cada uma com 2 linhas, no espaçamento $3 \times 3 \mathrm{~m}$. A distância entre renques foi de $22 \mathrm{~m}$, o que totalizou $20 \%$ por ha da área ocupada pelas faixas dos renques e densidade de 267 árvores.ha $^{-1}$.

O plantio do eucalipto africano foi realizado com aplicação de $300 \mathrm{~g}$ de fosfato natural de Arad (de origem sedimentar e orgânica) e de $100 \mathrm{~g}$ de super fosfato simples por cova. A adubação de cobertura foi realizada em maio de 2009, após o coroamento das mudas, com $60 \mathrm{~g}$ de ureia e $40 \mathrm{~g}$ de $\mathrm{KCl}$ por planta. No período de 2009 a 2011 realizou-se cultivos anuais de milho (2009/2010), soja (2010/2011) e milho (2011/2012), todos consorciados com Brachiaria ruziziensis e intercalado com eucalipto (Eucalyptus urophylla). Avaliou-se também um sistema Santa Fé manejado com cultivo de milho em consórcio com Brachiaria ruziziensis em 5 ha e um sistema Convencional ( $3 \mathrm{ha}$ ) manejado com técnicas tradicionais de preparo do solo (aração e gradagem) e controle fitossanitário.

Para fins deste estudo foi utilizado o híbrido BRS 1055 por apresentar destaque na produtividade e estabilidade de produção, sendo superior à maioria dos híbridos simples, em diversos tipos de ambientes, além disso, por possuir alta prolificidade, elevada tolerância ao acamamento e quebramento, e moderada resistência a doenças foliares. O milho BRS 1055 é de ciclo semiprecoce, de porte médio/alto, com grãos semidentados de cor vermelha e pode ser cultivado nas regiões Norte, Centro-Oeste, Sudeste, Nordeste e Estado do Paraná (Norte, Noroeste e Oeste do Estado), para plantios em safra e safrinha, sem restrição de altitude (GUIMARÃES et al., 2009).

O delineamento experimental utilizado foi o de blocos casualizados, com quatro repetições. Os tratamentos foram compostos por três cultivos de milho (BRS 1055), em sistema iLPF (consorciado com Brachiaria ruziziensis e intercalado com eucalipto, sistema Santa Fé (cultivo integrado com Brachiaria ruziziensis) e como testemunha um cultivo em sistema Convencional.

Em fevereiro de 2012, foi realizado o plantio do milho BRS 1055 em linhas no espaçamento $0,60 \mathrm{~m}$, após aplicação de glifosato, com adubação de base de 330 kg.ha ${ }^{-1}$ da formulação 10-28-20. Em março e maio, foram realizadas adubações de cobertura com $200 \mathrm{~kg}^{-h^{-1}}$ (Ureia $\left.+\mathrm{KCl}, 2: 1\right)$ e $180 \mathrm{~kg}$ (Ureia $\left.+\mathrm{KCl}, 2: 1\right)$, 
respectivamente. Em maio de 2012, foi semeada nos sistemas iLPF e Santa Fé a Brachiaria ruziziensis (20 kg.ha-1 $)$. A colheita do milho foi realizada mecanicamente em julho de 2012.

Para avaliação do milho foram coletadas amostras em três linhas de 5 metros lineares por faixa (área útil da parcela $10,5 \mathrm{~m}^{2}$ ), onde determinou-se: a altura (m) de planta e de inserção da primeira espiga, através da mensuração da base da planta rente ao solo até a folha bandeira e até o ponto de inserção, respectivamente, com uso de trena métrica; teor de umidade dos grãos (\%), obtido através da leitura direta, mediante uso de aparelho elétrico portátil determinador de umidade de grãos; produtividade de grãos (kg.ha-1 ${ }^{-1}$, saca.ha ${ }^{-1}$ e kg.planta $\left.{ }^{-1}\right)$, obtida a partir da debulha manual e pesagem dos grãos provenientes de todas as espigas colhidas na área útil $\left(10,5 \mathrm{~m}^{2}\right)$ das parcelas, o qual foi convertido para kg.ha ${ }^{-1}$ e corrigido para 130 g.kg ${ }^{1}$ de teor de água (b.u.); estande de plantas (número de plantas.ha ${ }^{-1}$ ), alcançado através da contagem de plantas na área útil $\left(10,5 \mathrm{~m}^{2}\right)$ das parcelas e convertido para plantas.ha ${ }^{-1}$.

Os resultados foram submetidos à análise de variância através do programa estatístico SISVAR ${ }^{\circledR}$ e quando significativo as médias foram comparadas pelo teste de Tukey $p<0,05$ (FERREIRA, 2011).

\section{RESULTADOS E DISCUSSÃO}

A altura de planta e altura de espiga não apresentaram diferença significativa em função dos sistemas utilizados, sendo 2,42 $\mathrm{m}$ a média para altura de planta com valor mínimo de 2,32 m para o sistema Santa Fé e valor máximo de 2,57 m para o sistema iLPF. A altura de espiga obteve média de $1,37 \mathrm{~m}$, sendo o valor mínimo 1,32 m para o sistema Santa Fé e valor máximo de 1,43 m para o sistema iLPF (Tabela 3). 
Tabela 3. Características agronômicas e produtividade do milho BRS 1055 em sistema iLPF, Santa Fé e Convencional

\begin{tabular}{|c|c|c|c|c|c|c|c|}
\hline \multirow[b]{2}{*}{ Sistemas* } & \multicolumn{2}{|c|}{ Altura } & \multirow[b]{2}{*}{$\begin{array}{l}\text { Umidade } \\
\text { colheita (\%) }\end{array}$} & \multicolumn{3}{|c|}{ Produtividade } & \multirow[b]{2}{*}{$\begin{array}{c}\text { Estande } \\
\text { (planta. } \\
\text { ha }^{-1} \text { ) }\end{array}$} \\
\hline & $\begin{array}{l}\text { planta } \\
(\mathrm{m})\end{array}$ & $\begin{array}{l}\text { espiga } \\
(\mathrm{m})\end{array}$ & & $\left(\mathrm{kg} \cdot \mathrm{ha}^{-1}\right)$ & $\begin{array}{l}\text { (saca. } \\
\left.\mathrm{ha}^{-1}\right)\end{array}$ & $\begin{array}{c}\text { (kg. } \\
\left.\text { planta }^{-1}\right)\end{array}$ & \\
\hline iLPF & $2,57 \mathrm{a}$ & $1,43 \mathrm{a}$ & $32,9 \mathrm{a}$ & $6133,77 \mathrm{a}$ & $102 \mathrm{a}$ & $0,13 \mathrm{a}$ & $47569 \mathrm{a}$ \\
\hline Santa Fé & $2,32 \mathrm{a}$ & $1,32 \mathrm{a}$ & $35,3 \mathrm{a}$ & $7213,67 \mathrm{a}$ & $120 \mathrm{a}$ & $0,14 \mathrm{a}$ & $50663 \mathrm{a}$ \\
\hline Convencional & $2,36 \mathrm{a}$ & $1,37 \mathrm{a}$ & $34,9 \mathrm{a}$ & $3479,55 \mathrm{~b}$ & $58 \mathrm{~b}$ & $0,09 \mathrm{~b}$ & $36946 \mathrm{~b}$ \\
\hline $\mathrm{CV}(\%)$ & 7,16 & 4,01 & 4,09 & 12,65 & 12,74 & 14,33 & 8,69 \\
\hline
\end{tabular}

*Médias seguidas da mesma letra minúscula na coluna não diferem pelo teste de Tukey $(p<0,05)$.

As variáveis altura de planta e espiga apresentaram coeficiente de variação (CV) de 7,16 e 4,01\%, respectivamente, e 12,65\% para a produção de grãos (kg.ha${ }^{1}$ ). A precisão experimental calculada pelo $\mathrm{CV}$ foi considerada normal com valores de CV abaixo de 15\%. Estes valores de CV corroboram aos de Ramella et al. (2013), no trabalho em que avaliaram a influência de quatro densidades de semeadura de Brachiaria brizantha na modalidade de consorciação com a cultura do milho, que apresentaram resultados de CV inferiores a 15\% para estas variáveis na cultura, sendo CV de 3,21\% (altura de planta), 6,24\% (altura de espiga) e 5,49\% (produtividade de grãos).

No estudo de Demétrio et al. (2008), a variável altura de planta no espaçamento 0,60 m e estande de 50.000 plantas.ha $^{-1}$ obteve valor semelhante ao deste trabalho com valor médio de $2,35 \mathrm{~m}$, entretanto, os valores de inserção da primeira espiga foram inferiores $(0,96 \mathrm{~m})$. Observaram também aumento dessas variáveis na medida em que aumentou-se a densidade populacional, não corroborando com os resultados obtidos neste trabalho, visto que o estande de plantas não influenciou as variáveis altura de planta e de inserção de espiga entre os diferentes sistemas.

Argenta et al. (2001) e Alvarez et al. (2006) obtiveram maiores alturas de plantas e de inserção da espiga com o aumento da densidade populacional, indicando uma tendência natural de aumento de altura de plantas em situações de alta densidade. De acordo com os resultados obtidos por Sangoi et al. (2002), a altura das plantas será tanto maior quanto maior o estande, em razão do efeito 
combinado da competição intraespecífica por luz, com consequente estímulo da dominância apical das plantas.

Já Takasu et al. (2014), obtiveram redução da altura da planta e espiga à medida que aumentou a população de plantas.ha ${ }^{-1}$, possivelmente devido à maior competição intraespecífica por água, nutrientes e radiação solar na linha para os maiores estandes.

Plantas de menor altura têm sido um caractere de interesse entre os produtores de milho por permitir cultivos em maiores densidades populacionais e maior eficiência na colheita mecânica, ao mesmo tempo em que diminui problemas associados ao acamamento e quebramento de plantas antes do ponto de colheita, comumente apresentado por plantas de porte alto (ALMEIDA et al., 2000). Além disso, a menor altura de planta permite maior transposição de luz no dossel (mesmo com alto índice de área foliar) e redução de competição intraespecífica por recursos naturais sob altos estandes de plantas (KAPPES, 2011).

Quanto à produtividade de grãos, os sistemas iLPF e Santa Fé apresentaram os maiores valores de produção (kg.ha ${ }^{-1}$ e saca.ha-1) não diferindo entre si. Notouse que os sistemas iLPF e Santa Fé possibilitaram maior produção por indivíduo calculando a produtividade (kg.ha-1) em razão do estande (plantas.ha ${ }^{-1}$ ), ou seja, em torno de $0,14 \mathrm{~kg}_{\text {.planta }}{ }^{-1}$, sendo essa produção cerca de $36 \%$ superior à obtida no sistema Convencional (Tabela 3).

De acordo com Calonego et al. (2011b), em determinada área o plantio de menores populações de plantas induz a redução da eficiência da radiação solar possibilitando aumento na produção de grãos por indivíduo, porém, reduz a produtividade por área. Por outro lado, maiores populações proporcionam maior produção por área e redução na produtividade por planta. A similar produtividade de grãos entre os sistemas iLPF e Santa Fé (Tabela 3) pode ser explicada pelo fato de não apresentarem populações superiores a 60.000 planta.ha $^{-1}$, pois segundo Ubert et al. (2014), populações acima desse valor tendem à redução na produtividade.

No período de colheita do milho no sistema iLPF, as árvores de eucalipto apresentavam altura média de $11,82 \mathrm{~m}$, ou seja, cerca de $360 \%$ superior à altura média do milho $(2,57 \mathrm{~m})$, demonstrando que as fileiras de árvores exerceram sombreamento sobre o milho. Contudo, essa semelhante produtividade de grãos 
com o sistema Santa Fé provavelmente está relacionada em função das árvores de eucalipto possuírem copa aberta e folhas subopostas e alternadas, lanceoladas e que se estreitam abruptamente em uma ponta curta (SELN; MITLÖHNER, 2011), ocasionando sombreamento falhado.

Alves et al. (2013), no estudo em que avaliaram a composição morfológica de híbridos de milho safrinha, cultivados no sistema solteiro e consorciado com B. ruziziensis apresentaram produtividade de grãos de $5.174 \mathrm{~kg} \cdot \mathrm{ha}^{-1}$ rendimento inferior ao obtido no presente estudo. A média de produtividade de grãos entre os sistemas iLPF e Santa Fé $\left(6.673,72 \mathrm{~kg} \cdot \mathrm{ha}^{-1}\right)$ foi superior à média estadual e nacional da safra 2014/15 (2.841 e 5.208 kg.ha-1 ${ }^{-1}$, respectivamente) (CONAB, 2015). Estes resultados superiores de produtividade provavelmente estão relacionados aos elevados números de precipitações pluviais (Tabela 2), pois permitiram bom desenvolvimento da cultura do milho devido à diminuição na competição por água (BERGAMASCHI et al., 2004).

O espaçamento entres linhas $(0,6 \mathrm{~m})$ utilizado no plantio de milho devido o consórcio com Brachiaria ruziziensis nos sistemas iLPF e Santa Fé resultou em maior produção de grãos por área e por planta em razão do milho exercer alta competição sobre a forragem auxiliando no aumento da produção de grãos (KLUTHCOUSKI et al., 2000). Verificou-se que a forragem não afetou o desenvolvimento do milho visto que a Brachiaria apresenta crescimento inicial lento (VALLE; PAGLIARINI, 2009) e as plântulas de milho crescimento inicial rápido. Segundo Barducci et al. (2009), o cultivo de milho não sofre queda na produtividade de grãos quando consorciado com forrageiras perenes, sendo confirmado neste estudo.

A Brachiaria ruziziensis em consórcio com milho auxiliou na redução dos riscos de erosão e compactação do solo pela chuva. Esse sucesso na utilização das Brachiarias ocorre em razão de seu sistema radicular apresentar em média 2,0 $\mathrm{m}$ de profundidade, de possuir excelente resistência à escassez hídrica, quando comparadas com espécies produtoras de grãos e por produzir alta quantidade de massa seca em torno de 20 t.ha $^{-1}$ (FERREIRA et al., 2010; CRUSCIOL et al., 2012).

Os renques de eucalipto no sistema iLPF agregaram valor à área visto que essa espécie florestal possui bom desenvolvimento nestes sistemas, rápido crescimento e idades de corte, além de diversificar a renda do produtor (MARTHA JR. et al., 2011). 
Os sistemas iLPF e Santa Fé auxiliaram no manejo sustentável do solo reduzindo a necessidade de abertura de novas áreas.

\section{CONSIDERAÇÕES FINAIS}

O cultivo de milho no sistema de integração Lavoura-Pecuária-Floresta interposto com eucalipto (Eucalyptus urophylla) e no sistema Santa Fé apresentou desenvolvimento superior quando comparado ao sistema Convencional.

A Brachiaria ruziziensis em consórcio com milho favoreceu o aumento na produção de grãos por área e por indivíduo em comparação ao sistema Convencional.

\section{AGRADECIMENTOS}

À Empresa Brasileira de Pesquisa Agropecuária, ao Projeto iLPF, Projeto PECUS e ao Banco da Amazônia pelo financiamento da pesquisa.

\section{REFERÊNCIAS}

AGUIAR, M. I.; MAIA, S. M. F.; XAVIER, F. A.; MENDONÇA, E. S.; ARAÚJO FILHO, J. A.; OLIVEIRA, T. S. Sediment, nutrient and water losses by water erosion under agroforestry systems in the semi-arid region in northeastern Brazil. Agroforestry Systems, v. 79, p. 277-289, 2010. DOI: 10.1007/ s10457-010-9310-2.

ALMEIDA, M. L.; MEROTTO JÚNIOR, A.; SANGOI, L.; ENDER, M.; GUIDOLIN, A. F. Incremento na densidade de plantas: uma alternativa para aumentar o rendimento de grãos de milho em regiões de curta estação estival de crescimento. Ciência Rural, Santa Maria, Porto Alegre, v. 30, n. 1, p. 23-29.

ALVAREZ, C. G. D.; PINHO, R. G.; BORGES, I. D. Avaliação de características agronômicas e de produção de forragens e grãos de milho em diferentes densidades de semeadura e espaçamentos entre linhas. Ciência e Agrotecnologia, v. 30, p. 402-408, 2006. 
ALVES, V. B.; CECCON, G.; LEITE, L. F. Morfologia e produtividade de híbridos de milho Safrinha solteiro e consorciado com braquiária. Revista Brasileira de Milho e Sorgo, v. 12, n. 2, p. 152-163, 2013.

ARGENTA, G. S.; SILVA, P. R. F.; SANGOI, L. Arranjo de plantas em milho: análise do estado da arte. Ciência Rural, v. 31, p. 1075-1084, 2001.

BALBINO, L. C.; CORDEIRO, L. A. M.; PORFIRIO-DA-SILVA, V.; MORAES, A.; MARTÍNEZ, G. B.; ALVARENGA, R. C.; KICHEL, A. N.; FONTANELI, R. S.; SANTOS, H. P.; FRANCHINI, J. C.; GALERANI, P. R. Evolução tecnológica e arranjos produtivos de sistemas de integração lavoura-pecuária-floresta no Brasil. Pesquisa agropecuária brasileira, Brasília, v. 46, n. 10, p. i-xii, out. 2011.

BARDUCCI, R. S.; COSTA, C.; CRUSCIOL, C. A. C.; BORGHI, É.; PUTAROV, T. C.; SARTI, L. M. N. Produção de Brachiaria brizantha e Panicum maximum com milho e adubação nitrogenada. Archivos de Zootecnia, Córdoba, v. 58, n. 222, p. 211222, 2009.

BERGAMASCHI, H.; DALMAGO, G. A.; BERGONCI, J. I.; BIANCHI, C. A. M.; MÜLLER, A. G.; COMIRAN, F.; HECKLER, B. M. M. Distribuição hídrica no período crítico do milho e produção de grãos. Pesquisa agropecuária brasileira. Brasília, v. 39, n. 9, p. 831-839, 2004.

BLACK, C. A. Methods of Soil Analisys: part 2 - Chemical and Microbiological Properties. Madison: Amaerican Society of Agronomy, p. 1159-1965.

BRINTHA, I.; SERAN, T. H. Effect of paired row planting of radish (Raphanus sativus L.) intercropped with vegetable amaranthus (Amaranthus tricolor L.) on yield components of radish in Sandy regosol. Journal of Agricultural Sciences, v. 4, p. 19-28, 2009.

CALONEGO, J. C.; BORGHI, E.; CRUSCIOL, C. A. C. Intervalo hídrico ótimo e compactação do solo com cultivo consorciado de milho e braquiária. Revista Brasileira de Ciência do Solo, Viçosa, v. 35, p. 2183-2190, 2011 a. 
CALONEGO, J. C.; POLETO, L. C.; DOMINGUES, F. N.; TIRITAN, C. S. Produtividade e crescimento de milho em diferentes arranjos de plantas. Revista Agrarian, Dourados, v. 4, n. 12, p. 84-90, 2011b.

COMPANHIA NACIONAL DE ABASTECIMENTO - CONAB. Safra 2014/15. Acompanhamento Safra Brasileira Grãos, v. 2, n. 7, Brasília, p. 1-100, abr. 2015.

CRUSCIOL, C. A. C.; BORGHI, E. Consórcio de milho com braquiária: produção de forragem e palhada para o plantio direto. Revista Plantio Direto, Passo Fundo, v. 16, n. 100, p. 10-14, jul./ago. 2007.

CRUSCIOL, C. A. C.; MATEUS, G. P.; NASCENTE, A. S.; MARTINS, P. O.; BORGHI, E.; PARIZ, C. M. An innovative crop-forage intercrop system: early cycle soybean cultivars and palisadegrass. Agronomy Journal, Madison, v. 104, n. 4, p. 1085-1095, 2012.

DEMÉTRIO, C. S.; FILHO, D. F.; CAZETTA, J. O.; CAZETTA, D. A. Desempenho de híbridos de milho submetidos a diferentes espaçamentos e densidades populacionais. Pesquisa Agropecuária Brasileira, Brasília, v. 43, n. 12, p. 1691-1697, dez. 2008.

EMPRESA BRASILEIRA DE PESQUISA AGROPECUÁRIA - EMBRAPA. Centro Nacional de Pesquisa de Solos. Sistema brasileiro de classificação de solos. 2. ed. Rio de Janeiro: Embrapa Solos, 2006.

EMPRESA BRASILEIRA DE PESQUISA AGROPECUÁRIA - EMBRAPA. Manual de métodos de análises do solo. Centro Nacional de pesquisa em solos. 2. ed. Rio de Janeiro: Ministério da Agricultura, 1997. 212f.

EMBRAPA CLIMA TEMPERADO. Reunião Técnica Anual de Milho LVIII Reunião Técnica Anual de Milho e XII Reunião Técnica Anual de Sorgo: indicações técnicas para o cultivo de milho e de sorgo no Rio Grande do Sul safras 2013/2014 e 2014/2015. Brasília, DF: Embrapa, 2013.

FERREIRA, A. C. B.; LAMAS, F. M.; CARVALHO, M. C. S.; SALTON, J. C.; SUASSUNA, N. D. Produção de biomassa por cultivos de cobertura do solo e produtividade do algodoeiro em plantio direto. Pesquisa Agropecuária Brasileira. Brasília, v. 45, n. 6, p. 546-553, 2010. 
FERREIRA, D. F. Sisvar: a computer statistical analysis system. Ciência \& Agrotecnologia, Lavras, v. 35, n. 6, p. 1039-1042, nov./dez., 2011.

GUEDES, R. E.; RUMJANEK, N. G.; XAVIER, G. R.; GUERRA, J. G. M.; RIBEIRO, R. L. D. Consórcios de caupi e milho em cultivo orgânico para produção de grãos e espigas verdes. Horticultura Brasileira, v. 28, p. 174-177, 2010. DOI: 10.1590/ S0102-05362010000200006.

GUimarãeS, P. E. O.; PARENTONI, S. N.; MEIRELleS, W. F.; PACHECO, C. A. P.; SILVA, A. R.; GUIMARÃES, L. J. M.; CARDOSO, M. J.; ROCHA, L. M. P.; COSTA, R. V.; OLIVEIRA, J. S.; COTA, L. V.; CARVALHO, H. W. L.; GODINHO, V. P. C.; CECCON, G.; MACHADO, A. T.; BASTOS, E. A.; VILARINHO, A. A.; SOUZA, F. R. S.; DIAS, W. P.; EMGYDIO, B. M.; GARCIA, J. C.; WRUCK, F. J.; CASELA, C. R. BRS 1055 - Híbrido Simples de Milho. Sete Lagoas: Embrapa Milho e Sorgo, 2009. 9p. (Comunicado técnico 176,)

INSTITUTO NACIONAL DE METEOROLOGIA - INMET. Estações e dados: Estações automáticas, gráficos. 2015. Disponível em: <http://www.inmet.gov.br/portal/index. php?r $=$ home/page\&page $=$ rede_estacoes_auto_graf $>$. Acesso em: 02 fev. 2015.

KAPPES, C.; ANDRADE, J. A. C.; ARF, O.; OLIVEIRA, A. C.; ARF, M. V.; FERREIRA, J. P. Desempenho de híbridos de milho em diferentes arranjos espaciais de plantas. Bragantia, Campinas, v. 70, n. 2, p. 334-343, 2011.

KLUTHCOUSKI, J.; COBUCCI, T.; AIDAR, H.; YOKOYAMA, L. P.; OLIVEIRA, I. P.; COSTA, J. L. S.; SILVA, J. G.; VILELA, L.; BARCELLOS, A. O.; MAGNABOSCO, C. U. Sistema Santa Fé - tecnologia Embrapa: integração lavoura-pecuária pelo consórcio de culturas anuais com forrageiras, em áreas de lavoura, nos sistemas direto e convencional. Santo Antônio de Goiás: Embrapa Arroz e Feijão, 2000. (Circular técnica 38).

MARTHA JUNIOR, G. B.; ALVES, E.; CONTINI, E. Dimensão econômica de sistemas de integração lavoura-pecuária. Pesquisa Agropecuária Brasileira, Brasília, v. 46, n. 10, p. 1117-1126, 2011. 
MOLUA, E. L. The economics of tropical agroforestry systems: the case of agroforestry farms in Cameroon. Forest Policy and Economics, v. 7, p. 199-211, 2005. DOI: 10.1016/S1389- 9341(03)00032-7.

NASCIMENTO, R. S.; CARVALHO, N. L. Integração-lavoura-pecuária. Monografias ambientais - REMOA/UFSM, Santa Maria, v. 4, n. 4, p. 828-847, 2011.

RAMELLA, J. R. P.; BATTISTUS, A. G.; SILVA, C.; LIBARDI, K. D. C.; CASTAGNARA, D. D.; OLIVEIRA, P. S. R.; NERES, M. A. Influência do sistema lavoura-pecuária com Zea mays L. e Brachiaria brizantha nas variáveis produtivas da cultura do milho. Scientia Agraria Paranaensis, v. 12, n. 2, p. 96-104, 2013.

SANGOI, L.; GRACIETTI, M. A.; RAMPAZZO, C.; BIANCHET, P. Response of Brazilian maize hybrids from different eras to changes in plant density. Field Crops Research, v. 79, p. 39-51, 2002.

SANTOS, R. D. Características agronômicas de variedades de milho para produção de silagem. Acta Scientiarum. Animal Sciences, v. 32, n. 4, p. 367-373, 2010.

SELN, C. C.; MITLÖHNER, R. Eucalyptus urophylla S.T. blake: ecology and silvicuture in Vietnam. Bogor: CIFOR, 2011. 26 p. Disponível em: < http://www. cifor.org/publications/pdf_files/Books/BCIFOR 1108.pdf $>$. Acesso em: 05 maio 2013.

SOUZA, E. D.; COSTA, S. E. V. G. A.; LIMA, C. V. S.; ANGHINONI, I.; MEURER, E. J.; CARVALHO, P. C. F. Carbono orgânico e fósforo microbiano em sistema de integração lavoura-pecuária submetido a diferentes intensidades de pastejo em plantio direto. Revista Brasileira de Ciência do Solo, Campinas, v. 32, p. 1273-1282, 2008.

SOUZA, L. S. B.; MOURA, M. S. B.; SEDIYAMA, G. C.; SILVA, T. G. F. Eficiência do uso da água das culturas do milho e do feijão-caupi sob sistemas de plantio exclusivo e consorciado no semiárido brasileiro. Bragantia, v. 70, p. 715-721, 2011.

TAKASU, A. T.; RODRIGUES, R. A. F.; GOES, R. J.; ARF, O.; HAGA, K. I. Desempenho agronômico do milho sob diferentes arranjos populacionais e espaçamento entrelinhas. Agrarian, Dourados, v. 7, n. 23, p. 34-41, 2014. 
UBERT, I. P.; ALMEIDA, C. A. S.; CHIODELLI, E.; BRESOLIN, F.; CASTANHO, M.; SOLIGO, S.; CAMILLO, M. F. Efeito de diferentes densidades na produtividade de grãos de milho (zea mays 1.) em espaçamento reduzido. RAMVI, Getúlio Vargas, v. 01, n. 01, jan./jun. 2014.

VALLE, C. B.; PAGLIARINI, M. S. Biology, citogenetics, and breeding of Brachiaria. In: SINGH, R. J. (Ed.). Genetic resources, chromossome engineering, and crop managements. Boca Raton: CRC, p. 103-152, 2009.

Recebido em: 09 de julbo de 2015 Revisado em:22 de dezembro de 2015 Aceito em: 27 de janeiro de 2016 